\title{
Evaluation of Local and Imported Fire Blight Warning Systems in Israel
}

\author{
D. Shtienberg, H. Shwartz, D. Oppenheim, M. Zilberstaine, Z. Herzog, S. Manulis, and G. Kritzman
}

First, second, sixth, and seventh authors: Department of Plant Pathology, ARO, The Volcani Center, Bet Dagan 50250, Israel; and third, fourth, and fifth authors: Extension Service, Ministry of Agriculture, Bet Dagan 50250, Israel.

Accepted for publication 5 November 2003.

\begin{abstract}
Shtienberg, D., Shwartz, H., Oppenheim, D., Zilberstaine, M., Herzog, Z., Manulis, S., and Kritzman, G. 2003. Evaluation of local and imported fire blight warning systems in Israel. Phytopathology 93:356-363.

The possibility of using local and imported warning systems for the management of fire blight (caused by the bacterium Erwinia amylovora) in pears was tested in Israel from 1997 to 2000. Three imported systems (MARYBLYT 4.3, BIS95, and Cougarblight 98C) and one local system (Fire Blight Control Advisory [FBCA]) were used. All systems were tested in simulation experiments; MARYBLYT 4.3 and FBCA were also tested in orchard experiments under natural infections. Simulation experiments included 193 orchard-plots in which the time of disease onset enabled us to determine the date of infection. Thirty-five experiments were conducted in commercial orchards; in 10 of these, fire blight

simulation experiments, the success rate (i.e., the capacity of the systems to predict the exact date of the occurrence of infection episodes) of the imported systems was low (3 to 55\%) with considerably large variability among years $(\mathrm{CV}=30$ to $67 \%)$. Similar results were obtained in the orchard experiments for MARYBLYT 4.3: in only two of five experiments where plots were managed according to that system was disease severity significantly lower than that recorded in untreated control plots. In comparison, the local system, FBCA, predicted most infection episodes in the simulation experiments with low variability $(99 \%, \mathrm{CV}=$ $1.0 \%$ ). In the orchard experiments, adequate disease suppression was achieved in all eight experiments in which FBCA recommendations were followed. We concluded that it was not possible to import and successfully implement fire blight warning systems in Israel that have been developed in regions with dissimilar environmental conditions.
\end{abstract} developed naturally. The performance of the imported warning systems was too variable to be accurately used under Israeli conditions. In the

Application of disease management measures when they are not needed is inefficient at best because their use results in unnecessary costs to growers, consumers, and perhaps to the environment (14). Growers, extension personnel, and farmer consultants are forced to seek assistance in their decision-making procedures because of complex interactions among the host, pathogen, and the environment. One approach for determining if or when to apply disease control measures is the use of disease forecasting or disease warning systems. Warning systems operate by predicting an outbreak or disease intensity based on weather, host, and/or pathogen conditions. Madden and Ellis (22) distinguish between fundamental and empirical warning systems. Fundamental warning systems are developed from experiments in the laboratory, controlled-environment chambers, greenhouses, or fields and describe one or more aspects of the host-parasite relationships as influenced by the environment. Empirical warning systems are developed from the observation and analysis of current and historical data on disease level and other biotic and abiotic factors. Empirical warning systems can be developed in one of two ways. The first approach, which is called qualitative, involves the development of prediction criteria ("rules") without any formal statistical analysis. The second, quantitative approach, is based on statistical analysis and modeling of the observed data (22).

Fire blight, caused by the bacterium Erwinia amylovora (Burrill) Winslow et al., is the most destructive pathogen of pears and other pome-fruit trees worldwide $(19,29,46,47)$. The epidemiology and disease cycle of E. amylovora have been reviewed in several publications $(19,29,42,47)$ and will not be elaborated upon here.

Corresponding author: D. Shtienberg; E-mail address: danish@ volcani.agri.gov.il

Publication no. P-2003-0110-01R

(c) 2003 The American Phytopathological Society
Additional keywords: integrated disease management, models.
The pathogen infects all plant parts including blossoms, shoots, leaves, fruits, limbs, and trunks. Effects of the disease are devastating, and severely infected trees may eventually die. Because of the erratic nature of fire blight, coupled with its destructive potential, management of this disease is a difficult task.

Prevention of blossom infection by E. amylovora is the key to fire blight management. Prior to infection, populations of $E$. amylovora can increase their size greatly through an epiphytic phase that occurs on floral surfaces. During this phase, the ultimate size of the pathogen population is influenced by temperature, which regulates the generation time of the pathogen $(19,43)$. Stigmas have been shown to be the primary site of epiphytic colonization by E. amylovora. Most recent studies support the hypothesis that blossom blight is the result of E. amylovora first colonizing stigmatic surfaces, followed by the external washing of cells from the stigma to the hypanthium where infection occurs (19). On the hypanthium, E. amylovora gains entry into the plant through nectarthodes located on the hypanthial surface (42). Therefore, rain or heavy dew at the end of a warm period promotes infection (19).

Bactericide sprays may prevent blossom infections but blossoms that open after spraying are not protected. Consequently, for optimal chemical protection, sprays should be applied frequently with short intervals between sprays to protect newly opened blossoms. This is not practical due to the cost of spraying and environmental considerations. Moreover, to lower the probability of resistance development in the pathogen population, spraying should be minimized. The solution is to apply the bactericides only when needed according to a warning system.

Investigations into the climatic factors influencing fire blight development, with a view to possibly predicting epidemics, were initiated in the 1920s (29). In the 1950s Mills (24) examined the use of weather information to improve spray timing. He performed a statistical correlation between New York weather data and 
fire blight incidence over 37 years, and developed simple rules that were used to time streptomycin sprays. In subsequent years, warning systems were developed by Powell working in Illinois (28), Billing in southeast England $(5,6)$, Thomson et al. in California (43), B. G. Zoller in California (9), Steiner in Maryland (40), Jaquart-Romon and Paulin in France (18), Smith in the Pacific Northwest (36), Berger et al. in southwestern Germany (4), and Shtienberg et al. in Israel (32). Although some of the fire blight warning systems rely on conclusions derived from laboratory experiments (e.g., effects of temperature on generation time of the bacterium), they all include rules that were developed without formal statistical analysis. Thus, they may all be considered qualitative empirical warning systems.

The pear production area in Israel covers 1,500 ha. The main cultivars are Spadona, Costia, and Jantil. Fire blight was first detected in Israel in 1985, and within two seasons, the disease had spread to all pear production areas in the country $(30,50)$. In the 10 years that followed, infections were scattered. In some cases, epidemics in individual orchards were severe, leading to yield damage, death of trees, and uprooting of entire orchards. Nevertheless, the intensity of the disease, regional and nationwide, was mild. The situation was different from 1994 to 1996, when severe epidemics developed in the main pear production areas. As a result, a national research and development project named the fire blight management (Fire-Man) project, was initiated in 1997 (34). As part of this effort, a comprehensive survey was conducted in pear orchards in the main production areas of the country. Analysis of disease onset records and weather data revealed that only a few (one to three) infection episodes occurred in individual orchards each year (33). Thus, a few properly timed bactericide sprays could provide adequate protection to the blossoms. The problem is to predict accurately when infection episodes are likely to happen. To find a tool that can be safely used by Israeli growers, we examined several warning systems that had been developed for fire blight management in other places as well as a system that had been developed in Israel. Imported systems were MARYBLYT 4.3 (41), BIS95 (7), and Cougarblight 98C (37), and the local system was the Fire Blight Control Advisory (FBCA) (32). All imported systems were tested and found accurate in their locations of origin $(8,21,37)$. All systems had been tested in simulation experiments; MARYBLYT 4.3 and FBCA were also tested in orchard experiments under natural infections.

\section{MATERIALS AND METHODS}

Description of the warning systems. Three imported and one local fire blight warning systems were used in this study. Some details on these various warning systems are given here; full descriptions of the systems are given elsewhere $(7,32,37,41)$. The first version of MARYBLYT, developed by Steiner and coworkers, was published in 1990 (40); version 4.3 of the system was released in 1996 (41). MARYBLYT is a comprehensive model, which identifies conditions conducive to the development of fire blight symptoms (blossom, canker, shoot, and trauma blight). Criteria for blossom infection are as follows: (i) the blossom must be open with stigmas and petals intact; (ii) passage of at least 110 cumulative degree-hours above $18.3^{\circ} \mathrm{C}$ from the first open bloom; (iii) a wetting event occurring as dew, $\geq 0.25 \mathrm{~mm}$ of rain, or $\geq 2.5 \mathrm{~mm}$ of rain on the previous day; and (iv) an average daily temperature $\geq 15.6^{\circ} \mathrm{C}$. Blossom blight symptoms will appear after 57 cumulative degree-days above $12.7^{\circ} \mathrm{C}$. With the four conditions for blossom blight predicted, treatments can be scheduled for the day before or the day of an infection. MARYBLYT was applied to apples and pears.

E. Billing, working in England, developed a system aimed at determining risks of blossom infection. Billing's Integrated System, 1995 (BIS95) evolved from earlier versions (Billing's Original System [BOS] and Billing's Revised System [BRS]) and some features of the MARYBLYT model (7). Features of BIS95 (related to blossom infection) include the following: (i) weather data recording at $0700-0900 \mathrm{~h}$; and (ii) the use of a degree-days sum based on a maximal temperature of $18^{\circ} \mathrm{C}$ (DD18-max.) during bloom to predict infection risk. Blossom infection may occur when simultaneously, at least 17 degree-days accumulate, heavy dew, mist or rain wets the blossoms, and the mean temperature is $15^{\circ} \mathrm{C}$ or more on the day of wetting. Allowance is made for possible blossom infection without wetting when maximal temperature is $\geq 27^{\circ} \mathrm{C}$ and/or mean temperature is $\geq 20^{\circ} \mathrm{C}$; use of warmth/ wetness scores for infection risk days when ooze is the source of inoculum, and the use of a degree-days sum based on a mean temperature of $13^{\circ} \mathrm{C}$ (DD13-mean) to time searches for signs of new disease. Early signs of the disease and fresh ooze are likely when DD13-mean reaches 17 or more. BIS95 can be used by fruit growers who have simple meteorological equipment at their disposal (minimum and maximum temperature with rain gauge), as well as by those who employ automatic orchard monitoring. Data are easily tabulated and graphics can be prepared with or without a computer. BIS95 was applied to hawthorn, as well as to apple and pear $(7,8)$.

The incidence of fire blight infection and the circumstances present in the orchard at the time of probable infection were monitored in pear and apple orchards of north-central Washington, and used in the development of an empirical fire blight infection risk evaluation model named Cougarblight 98C (37). This is an updated version of the original warning system (Smith model) developed in 1993 (36). According to Cougarblight 98C, the relative risk of fire blight is calculated each day that blossoms are open in the orchard. The high and low temperatures are used to calculate degree-hour values for the previous 4-day period. The degreehours calculation is based on an asymmetric curve adjusted to a base temperature of $15.5^{\circ} \mathrm{C}$, with an optimum peak of $31^{\circ} \mathrm{C}$. Degree-hour values decline to a minimum of $40.5^{\circ} \mathrm{C}$, above which bacterial numbers are assumed to decline slightly. Risk is dependent on the presence or past presence of fire blight and leftover cankers. Tables are provided to determine degree-hours and to evaluate infection risks. Application of control measures is recommended when the risk level is high or extreme, provided that the blossoms have been wetted by rain $(\geq 2 \mathrm{~mm}$ ) or dew (wetness $\geq 3 \mathrm{~h}$ ).

The FBCA was developed recently in Israel by Shtienberg et al. (32). The decision-making procedure in the FBCA comprises three major steps: (i) determine the potential risk for disease outbreak, and the parameters that contribute to that risk are analyzed and quantified. Parameters relate to the host (tree age, crop phenological stage, degree of shoot growth, and cultivar susceptibility), the pathogen (previous and current disease intensity and pathogen activity in the orchard and in neighboring orchards), and the grower's actions (sanitation and previous bactericide spraying). However, even if the level of potential risk is high, its realization depends on the existence of a conducive environment; (ii) estimate the suitability of the weather to disease outbreak. Temperature (minimum, maximum, and average) and duration of wetness measured on the previous 3 days are used to estimate the likelihood that infections already occurred. Maximum temperatures and rain forecasts for the following 2 days are used to estimate the likelihood of future infections. Estimates of the risk level and the weather's suitability are integrated to give a final measure of the likelihood of past and future infections; and (iii) the FBCA provides recommendation for action (i.e., apply bactericide today, tomorrow, or do not spray).

The fire blight survey. The fire blight survey was conducted from 1996 to 2000 and covered one-quarter to one-half of the pear production area of Israel. Full details on the data recorded and the results of the survey are given by (33). Data recorded from 1997 to 2000 were used in the simulation experiments reported here. Below, we provide the information relevant to the simulation 
experiments. The number of orchards and the area surveyed each year were 165 (745 ha) in 1997, 176 (830 ha) in 1998, 165 (490 ha) in 1999, and 109 (410 ha) in 2000. Data were recorded in the orchards before, during, and after bloom. Before bloom (December to February), growers provided information on the prevalence of fire blight and its intensity in their orchards in the previous spring and fall seasons, and the sanitation actions they had performed. During bloom (March to May), observations were made in the orchards and the date of fire blight onset and its subsequent severity, as well as the phenological stages of the trees (i.e., date of green tip, first bloom, full bloom, and petal fall) were recorded. After bloom (June and July), final severity of the disease and the management actions employed were recorded. Trained employees interviewed the growers, collected the data, and made the observations in the orchards. In some cases, infected blossom clusters, shoots, or branches were taken to the laboratory for identification of the causal agents. Bacteria were isolated on CCT media (17) and identified by polymerase chain reaction (PCR) using the primers and amplification conditions described by Bereswill et al. (3). In all cases, the causal agent was confirmed to be $E$. amylovora (33).

The database was organized in records. Each record included information concerning a specific orchard or a portion of an orchard that shared similar characteristics. For example, an orchard planted with three different pear cultivars was considered as three different records. Similarly, an orchard in which the trees were planted in two different years was considered as two different records. The number of records in 1997 was 406, and from 1998 to 2000 it was 542, 338, and 336, respectively. Thus, the basic unit for data analyses was "a record" as defined here and not "an orchard" as usually defined by growers. A record will be referred to hereafter as an "orchard-plot".

The pear production area in northern Israel was divided into 12 subregions based on topo-climatic considerations. An automatic weather station (Campbell Scientific Inc., Logan, UT) was placed in the center of each subregion and the following weather variables were recorded daily: (i) minimum and maximum temperature $\left({ }^{\circ} \mathrm{C}\right)$; (ii) duration of wetness (hours); and (iii) rain (millimeters in some of the stations). Temperature was measured with copper-constantan thermocouples, leaf wetness measured with the 237 wetness-sensing grid (Campbell Scientific Inc.), and rain was measured with a rain gauge. Sensors were placed at a height of $2 \mathrm{~m}$. The distance between each weather station and the pear orchards in the same subregion was, in most cases, less than 2 to $3 \mathrm{~km}$ and never exceeded $5 \mathrm{~km}$. The location of the weather stations (representing the various subregions) is mentioned elsewhere (33).

Simulation experiments. The simulation experiments included only those orchard-plots in which it was possible to determine the date of infection. Date of infection was determined separately for each orchard-plot based on the date of disease onset, and the weather data recorded earlier from the initiation of flowering. Of 1,622 orchard-plots included in the survey from 1997 to 2000, the records of disease onset were regarded as accurate in 285 and were further evaluated for inclusion in the simulation experiments. In these orchard-plots, orchard inspection was performed fre- quently (every 1 to 3 days), and the regional extension officer confirmed that the symptoms were indeed fire blight. Weather on the 5 to 25 days preceding the date of symptom observation and the dates of bactericide spraying were used to determine the date of infection. Because oxolinic acid is highly effective against $E$. amylovora (35), disease severity in orchard-plots treated just before or soon after the occurrence of infection episodes was low. On the other hand, in orchard-plots that were not treated at all or where sprays were improperly timed, disease severity was occasionally high (33). More details on the process of infection date determination are given in the Results section. Of the 285 orchardplots in which the data on fire blight onset were accurate, it was possible to determine the date of infection in 193. These orchardplots were located in 9 to 10 subregions; 20 were recorded in 1997, 39 in 1998, 38 in 1999, and 96 in 2000.

The various warning systems were operated employing the weather data actually recorded in the subregional weather stations. Thus, the forecast module of FBCA was not used in the simulation experiments. As rains in mid-March to late April are scattered and infrequent in Israel, and because the main source of wetness is dew, all systems were operated based on wetness duration data. MARYBLYT 4.3 and BIS95 require rain data for operation, although their developers indicate that heavy dew is sufficient for infection $(7,41)$. In a set of preliminary simulation experiments, the success rate (as defined below) of MARYBLYT 4.3 and BIS95 was low when the systems were operated based on rain data or when 4 or more hours of daily wetness were used as criteria for infection. Accordingly, in the simulation experiments presented here, MARYBLYT 4.3 and BIS95 were operated using a daily wetness of $2 \mathrm{~h}$ as the moisture threshold triggering infection. Cougarblight $98 \mathrm{C}$ can be operated based on rain or wetness data (37), and the FBCA requires wetness duration data exclusively (32). Infection risks determined by Cougarblight 98C and FBCA depend on the potential of pathogen presence in the orchard. In the simulation experiments, both systems were operated on the assumption of high potential pathogen presence. Using a low wetness threshold $(2 \mathrm{~h})$ instead of rain for MARYBLYT 4.3 and BIS95, and assuming a high potential pathogen presence in all orchard-plots for Cougarblight $98 \mathrm{C}$ and FBCA, presents the most severe scenarios. It is likely that the situation was less severe in reality, that is, $2 \mathrm{~h}$ of wetness was not necessarily sufficient for infection in all cases, and the potential of pathogen presence was not high in all orchard-plots. Nevertheless, the most severe scenarios were chosen purposely as the goal was to determine if the systems would identify all infection episodes. Thus, in the simulation experiments we attempted to lower the likelihood of false-negative predictions by the systems (i.e., situations in which the systems would not predict infection episodes that actually happened).

Two sets of simulation experiments were conducted. In the first, we determined whether the infection alerts issued by the warning systems coincided with the dates of infection. Success was declared in cases in which the warning systems issued infection alerts exactly on time (i.e., at the date of infection). In the second set of simulation experiments, we assumed that chemical pro-

TABLE 1. Dates of oxolinic acid spraying in the orchard experiments conducted for the evaluation of fire blight warning systems

\begin{tabular}{|c|c|c|c|c|}
\hline Year & Experiment & 5-day schedule & FBCA & MARYBLYT 4.3 \\
\hline \multirow[t]{2}{*}{1997} & 1 & 22 and 27 March; 4, 8, 14, 18, and 21 April & $\ldots$ & 3, 15, and 21 April \\
\hline & 2 & $3,8,14,18$, and 21 April & & 3, 18, and 21 April \\
\hline \multirow[t]{2}{*}{1998} & 1 & 22 and 27 March; 1, 7, and 13 April & 22 March; 1, 7, and 13 April & 22 March; 1, 7, and 13 April \\
\hline & 3 & 27 March; 4, 8, and 12 April & 29 March; 4 April & 8 and 12 April \\
\hline \multirow[t]{3}{*}{1999} & 1 & 29 March; 4, 10, and 14 April & 31 March; 4 and 12 April & $\ldots$ \\
\hline & 2 & 18, 23, and 28 March; 5, 9, 14, and 19 April & 18 March; $1,5,9$, and 14 April & $\ldots$ \\
\hline & 3 & 19, 24, and 29 March; 5 and 9 April & 24 March; 5 and 9 April & $\ldots$ \\
\hline
\end{tabular}


tection would be applied based on the predictions of the warning systems. Sprays were scheduled at the dates of infection alerts, provided that sprays had not been scheduled on the preceding 4 days. A recent study found oxolinic acid to be effective at protecting blossoms against E. amylovora if applied as much as 4 days before or as much as 2 days after the occurrence of infection (35). Thus, in this set of experiments, success was declared in cases in which sprays were scheduled within this time range surrounding the date of infection. The number of sprays that would have been applied in each orchard-plot for the duration of flowering was determined for each warning system. For comparison, a 5-day spraying schedule was simulated as well. For each year, the success rate was calculated for each warning system as the proportion (in percentage) of orchard-plots in which the alerts were properly timed. A $\chi^{2}$ test was used to determine whether the mean success rate (for the 4 years of the study) for each warning system differed significantly $(P \leq 0.05)$ from the maximal possible success rate $(100 \%)$.

Orchard experiments. The MARYBLYT 4.3 and FBCA systems were tested in 35 orchard experiments conducted from 1997 to 2000 . Seven experiments were conducted in 1997, nine in 1998, ten in 1999, and nine in 2000. MARYBLYT 4.3 was tested in 16 experiments in 1997 and 1998 and FBCA was tested in 28 experiments from 1998 to 2000. Experiments were conducted in commercial orchards located in most pear production areas of the country. The experiments were conducted in orchards that had not been infected at all in the previous season, as well as in orchards that had been moderately or severely infected in the previous season. Trees in the experiments were not artificially inoculated so natural infections were expected. The experiments included three or four treatments: (i) untreated control; (ii) application of oxolinic acid on a 5-day schedule during bloom; (iii) application of oxolinic acid according to MARYBLYT 4.3 predictions (in 1997 and 1998); and (iv) application of oxolinic acid according to FBCA predictions (from 1998 to 2000).

The bactericide oxolinic acid (20\% WP, Starner, Sumitomo Chemicals, Osaka, Japan) was applied by means of a hand-gun sprayer at $300 \mathrm{mg}$ a.i./liter in 1,000 liter of water/ha. In the 5-day treatment, the first spray was applied soon after the initiation of flowering; subsequent sprays were applied at 4- to 6-day intervals until the termination of flowering. The number of sprays in the 5-day schedule treatment varied from experiment to experiment according to the duration of flowering and ranged from three to seven sprays. Sprays in the MARYBLYT 4.3 and FBCA treatments were timed according to the prediction of the systems. The dates of spraying in the experiments where fire blight developed naturally and where the systems' performances were evaluated are presented in Table 1. Experimental plot size was four to six pear trees in a row and there were four or five replicates per treatment. Experimental design (completely randomized or complete block design) was determined in each experiment according to the physical arrangement of the trees.

Natural infections developed in 18 of 35 experiments. Disease severity was recorded in 10 of the experiments where epidemics developed at intensities sufficient to enable reliable data analysis and interpretation in terms of the efficacy of the warning systems. Disease was assessed visually on the two or three trees located in the center of each experimental plot. Two trained employees inspected the trees from both sides and counted the number of infected blossom clusters as a measure of disease severity. Assessments were made several times after the first observation of disease symptoms until disease severity increased no further. In this report, counts from the last assessments are presented. Data were analyzed by appropriate analysis of variance (ANOVA) tests at $P \leq 0.05$ and whenever the $F$ test detected significant effects, Fisher's protected LSD test was employed to identify the differences among treatments. In some cases, infected blossom clusters, shoots, or branches were taken to the laboratory for identification of the causal agents by PCR. In all samples, the causal agent was confirmed to be E. amylovora.

\section{RESULTS}

Simulation experiments. The first step was to sort the data recorded in the fire blight survey to identify the orchard-plots that could be used in the simulation experiments. This was done as follows. The date of fire blight symptoms in each orchard-plot was plotted together with the daily temperature and wetness data recorded in the relevant subregional weather station. The graphs were inspected and attempts were made to determine, for each orchard-plot, the date(s) of infection. In some orchard-plots it was not possible to identify the date of infection. For example, data recorded in an orchard-plot located in Kibbutz Regba in 2000 are plotted in Figure 1. In that orchard-plot, flowering was initiated on 1 April, and the first disease symptoms were observed on 22 April. Examination of weather data recorded before that date in the Regba weather station suggests that temperature and duration of wetness were conducive to infection on numerous days (Fig. 1). Thus, it was not possible to determine, with high probability, when infections might have occurred.

In other orchard-plots, however, it was possible to determine the date of infection. Examples for orchard-plots located in Rosh Pina from 1998 to 2000 are presented in Figure 2. In 1998, flowering was initiated on 26 March, and first disease symptoms were observed on 5 April. Analysis of temperature and wetness duration revealed that infection in that orchard-plot occurred on 30 and/or 31 March. In other orchard-plots located in the Rosh Pina subregion, first fire blight symptoms were observed between 4 and 7 April (result of the 30 and 31 March infection episode) and between 15 and 17 April (result of infections that occurred on 5 April). In 1999, flowering in the sample orchard-plot was initiated on $28 \mathrm{March}$, and fire blight symptoms were observed for the first time on 12 April, presumably as a result of infection that occurred on 1 April. In other orchard-plots located in the Rosh Pina subregion, first fire blight symptoms were observed from 12 to 15 April (result of the 1 April infection episode) and from 16 to 19 April (result of infections that occurred on 7 April). In 2000, flowering in the sample orchard-plot was initiated on 28 March, and fire blight symptoms were observed on 12 April as a result of infections that occurred on 4 and/or 5 April. In other orchard-plots located in the Rosh Pina subregion, first fire blight symptoms were observed from 12 to 15 April (result of the 4 and 5 April infections) and from 18 to 21 April (result of infections that occurred on 8 to 10 April) (Fig. 2).

Only the orchard-plots in which the date of infection could be determined were included in the simulation experiments. The vari-

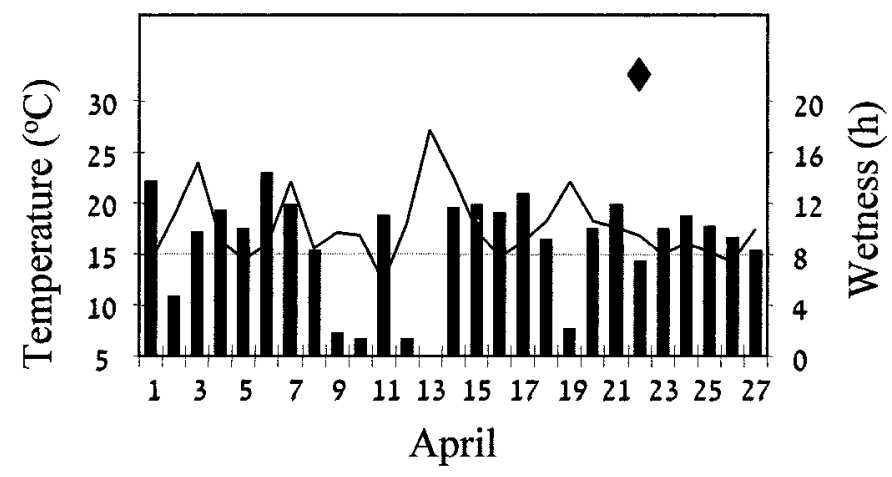

Fig. 1. Weather parameters recorded from the initiation of flowering and time of fire blight (caused by Erwinia amylovora) onset in an orchard located in Kibbutz Regba, Israel, in 2000. Line = mean daily temperature, bars = daily duration of wetness, and diamond = time of disease onset. Rain did not fall in Regba during April 2000. 
ous warning systems were operated based on the weather data, and the infection alerts issued by the warning systems were compared with the actual dates of infection. Examples for the sample orchard-plots located in Rosh Pina from 1998 to 2000 are presented in Figure 2. In 1998, only the FBCA system correctly predicted that infections would occur on the actual date. In 1999, FBCA and Cougarblight $98 \mathrm{C}$ predicted infections on the actual date of infection; MARYBLYT 4.3 and BIS95 predicted that in-
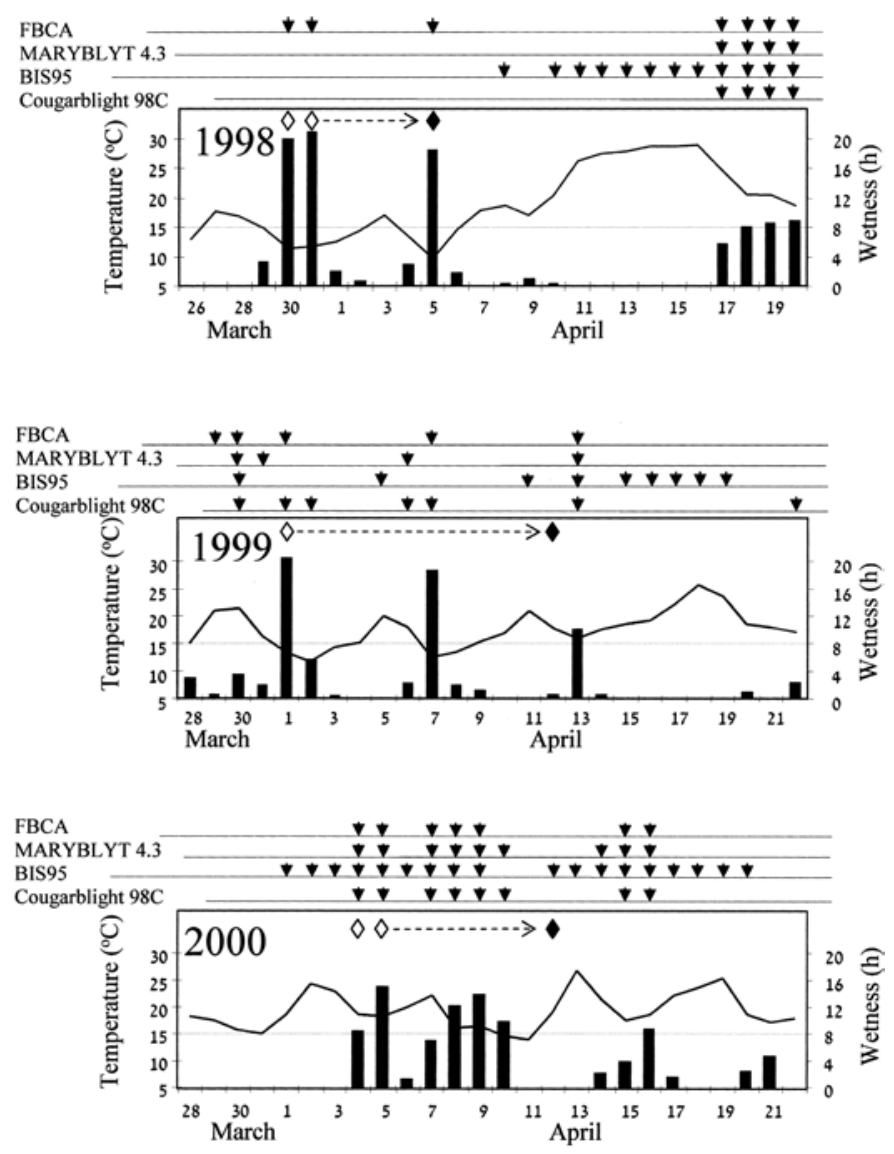

Fig. 2. Weather parameters recorded from the initiation of flowering and time of fire blight (caused by Erwinia amylovora) onset in three orchards located in Rosh Pina, Israel, from 1998 to 2000. Lines = mean daily temperature, bars $=$ daily duration of wetness, open diamonds $=$ the presumed date(s) of infection, dashed horizontal arrows = the incubation period, and filled diamonds $=$ time of disease onset. The filled triangles above each graph indicate the alerts for infection issued by four fire blight warning systems: the Fire Blight Control Advisory (FBCA), MARYBLYT 4.3, Billing's Integrated System, 1995 (BIS95), and Cougarblight 98C. Rain ( $\geq 2$ $\mathrm{mm}$ ) fell in Rosh Pina on 30 and 31 March and 5 April 1998, 1, 2, and 7 April 1999, and 9 and 21 April 2000. fection would occur 1 or 2 days earlier. In 2000, all four systems predicted that infections would occur on the actual dates (Fig. 2).

Of the 1,622 orchard-plots recorded in the fire blight survey, the actual date of fire blight infection could be determined in 193 . Simulations conducted for those 193 orchard-plots enabled testing of the compatibility of the various warning systems to Israeli conditions. The mean number of infection alerts per orchard-plot did not vary markedly among the four warning systems (2.5 to 4.9), although there was considerable year-to-year variation in the number of alerts issued by some of the systems (e.g., BIS95) (Table 2). However, there was a large difference in the success rate achieved by the systems: only the local system, FBCA, predicted the occurrence of most infection episodes (99.2\% on average) with low year-to-year variation. The mean success rates of the imported systems were relatively low (29.4 to $38.2 \%)$ and there was considerable year-to-year variation in those rates (Table 2).

The number of sprays that would have been applied had the recommendations of the systems been followed ranged from 1.4 to 2.7 on average for the warning systems to 6.4 sprays for the 5-day spraying schedule (Table 3). Although the success rate of MARYBLYT 4.3, BIS95, and Cougarblight 98C improved when blossom protection was used as a criterion for success (51.1 to $54.9 \%$ ), it was still significantly lower than the maximal possible success rate $(100 \%)$. Moreover, the year-to-year variation in the success rate was still considerably large $(\mathrm{CV}=30.9$ to $39.4 \%)$. The success rate of FBCA was similar to that of the 5-day spraying schedule, $100 \%$ (Table 3).

Orchard experiments. The efficacy of the MARYBLYT 4.3 and FBCA systems for fire blight management was evaluated from 1997 to 2000 in 35 experiments conducted in commercial orchards under natural infections. All experiments also included untreated and 5-day schedule treatments for comparison. Fire blight severity was assessed in 10 of the experiments. In all 10, disease severity in plots treated with oxolinic acid on a 5-day schedule was significantly lower than in the untreated control plots. In two of the experiments where sprays were scheduled according to MARYBLYT 4.3, fire blight was suppressed significantly as compared with untreated control plots (experiments 1 in 1997 and 1998). However, in the other experiments, differences between these treatments were insignificant (Table 3). In the eight experiments where FBCA was used, fire blight severity was significantly lower than that recorded in untreated control plots, and control efficacy in the FBCA-treated plots did not differ significantly from that achieved in plots treated with oxolinic acid on a 5-day schedule (Table 4). In the 35 experiments conducted from 1997 to 2000, the number of sprays applied in plots managed according to either MARYBLYT $4.3(2.6 \pm 0.17)$ or FBCA $(2.7 \pm$ 0.18 ) was significantly lower than the number of sprays applied in the 5-day schedule treatment $(4.75 \pm 0.19)$, as determined by a paired $t$ test $(P \leq 0.05)$. Differences in the number of sprays applied in plots treated according to the two warning systems were insignificant $(P=0.05)$.

TABLE 2. Performance of fire blight warning systems in simulation experiments. Systems were operated based on weather data recorded in subregional weather stations in northern Israel and their ability to identify the presumed dates of infection was tested. The simulations included 193 orchard-plots recorded in the fire blight survey from 1997 to 2000

\begin{tabular}{|c|c|c|c|c|c|c|}
\hline \multirow[b]{2}{*}{ Warning system ${ }^{z}$} & \multicolumn{3}{|c|}{ No. of infection alerts ${ }^{x}$} & \multicolumn{3}{|c|}{ Success rate $(\%)^{\mathrm{y}}$} \\
\hline & Range & Mean & $\mathrm{CV}(\%)$ & Range & Mean & $\mathrm{CV}(\%)$ \\
\hline FBCA & $3.7-5.7$ & 4.7 & 10.6 & $96.2-100.0$ & 99.2 & 1.0 \\
\hline MARYBLYT 4.3 & $0.1-6.5$ & 2.5 & 56.0 & $0.0-100.0$ & $38.2 *$ & 56.8 \\
\hline Cougarblight 98C & $1.0-5.8$ & 3.1 & 35.4 & $13.1-56.7$ & $34.3 *$ & 25.7 \\
\hline
\end{tabular}

${ }^{x}$ The number of times that the various warning systems predicted the occurrence of infection episodes in simulations conducted for the 4 years of the study. $\mathrm{CV}=$ year-to-year coefficient of variation (standard deviation/mean $\times 100$ ).

${ }^{\mathrm{y}}$ The proportion (in percentage) of cases in which the warning system predicted that infections would occur exactly at the date of infection. Asterisks indicate that the success rate differs significantly from the maximal success rate (100\% success), as determined by $\chi^{2}$ test (at $P \leq 0.05$ ).

${ }^{\mathrm{z}} \mathrm{FBCA}=$ the Fire Blight Control Advisory system; BIS95 = Billing's Integrated System, 1995. 


\section{DISCUSSION}

There is general agreement that warning systems, either locally developed or imported, should be adequately tested before implementation and used on a large scale $(8,9,22,36)$. When the goal of experimentation is to test the predictive accuracy of the warning systems, artificial inoculations are out of the question and experiments have to rely exclusively on natural infections. In some pathosystems, the likelihood of disease development in certain sites is high. This is, for example, the situation with Alternaria solani, the causal agent of potato early blight. With such diseases, it is relatively easy to set up experiments aimed at examining the accuracy of warning systems (31). However, when disease appearance is sporadic in space and time, experimentation becomes more difficult, making epidemiological studies and orchard trials difficult to plan and the relative value of different approaches to risk assessment difficult to estimate. Fire blight in pears is a good example of such a disease. Severe outbreaks of fire blight may occur in orchards with no history of the disease and similarly, symptoms occasionally do not develop in orchards following seasons with significant blight damage $(7,33,48)$. This fact constitutes a serious problem for fire blight experimentation since the likelihood of occurrence of natural infections with uniform distribution of the disease, in an experimental site, is not high. Accordingly, Billing (9) concluded that fire blight is too sporadic to enable good comparisons of the validity and precision of warning systems in orchard trials. Alternatively, she suggested using well-documented test cases for validation of the warning systems (7) and set a goal of collecting 200 complete cases for that purpose.

Of the 1,622 orchard-plots included in the survey, $193(11.9 \%)$ were regarded as accurate enough to be used in the simulation experiments. Thus, we were close to the 200-case goal set by E. Billing. Moreover, despite the difficulty involved in orchard experimentation, attempts were also made to test the warning systems under natural infections in commercial orchards. This was done by conducting a large number of experiments under diverse climatic conditions, in the hope that a reliable estimation of treatment effects would be possible in at least some of them. As part of the Fire-Man project, 35 orchard experiments were conducted from 1997 to 2000 in all pear-growing regions of the country. Natural infections developed in 18 of the experiments and in 10 of them $(28 \%)$, it was possible to analyze the data and detect significant differences among the applied treatments.

Points related to the simulation experiments should be emphasized: (i) as the simulation experiments were based on the assumption that the date of infection was known, only those orchard-plots in which it was possible to determine, with high probability, the dates of infection were used. Data of bactericide spraying in the orchards (that were also collected in the survey) assisted in determining the infection dates; (ii) more than one infection episode occurred in some of the orchard-plots. Since it was not possible to precisely determine the date of initial symptom appearance resulting from the second (and third) infections, only the first infection episodes in each orchard-plot were considered in the simulation experiments; and (iii) in view of the destructive nature of E. amylovora, risks resulting from falsenegative predictions (i.e., uncontrolled epidemics) are markedly more dangerous than risks resulting from false-positive predictions (i.e., unnecessary application of sprays). Accordingly, MARYBLYT 4.3 and BIS95 were operated based on wetness rather than rain data. These modifications were expected to decrease the occurrence of false-negative predictions, and hence, increase the success rate of the systems. At the same time, it was likely that these modifications would increase the occurrence of false-positive predictions, but this was felt to be more acceptable.

Based on the experiments conducted in this study, it was concluded that the performance of the imported fire blight warning systems is too variable for their accurate use under Israeli conditions. In the simulation experiments, the success rate of the imported systems was insufficient for both criteria of success used, with a wide range of success rate among years and considerably large variation $(\mathrm{CV}=30$ to $67 \%)$. Thus, despite our modification of the systems, the proportion of false-negative predictions was high. The local system, FBCA, on the other hand, predicted most infection episodes with low variation (Tables 2 and

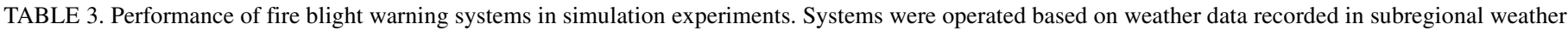

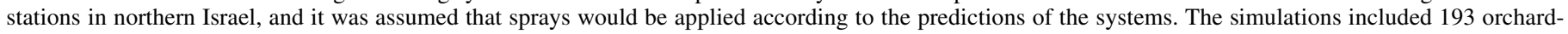
plots recorded in the fire blight survey from 1997 to 2000

\begin{tabular}{|c|c|c|c|c|c|c|}
\hline \multirow[b]{2}{*}{ Warning system ${ }^{\mathrm{z}}$} & \multicolumn{3}{|c|}{ No. of sprays ${ }^{x}$} & \multicolumn{3}{|c|}{ Success rate $(\%)^{\mathrm{y}}$} \\
\hline & Range & Mean & $\mathrm{CV}(\%)$ & Range & Mean & $\mathrm{CV}(\%)$ \\
\hline 5-days & $5.3-7.3$ & 6.4 & 7.8 & $\ldots$ & 100.0 & 0.0 \\
\hline FBCA & $2.2-3.6$ & 2.7 & 11.1 & $\ldots$ & 100.0 & 0.0 \\
\hline MARYBLYT 4.3 & $0.1-2.6$ & 1.4 & 35.7 & $8-100$ & $52.5 *$ & 39.4 \\
\hline BIS95 & $1.1-3.8$ & 2.1 & 28.6 & $25-100$ & $54.9 *$ & 30.9 \\
\hline Cougarblight $98 \mathrm{C}$ & $1.0-2.6$ & 1.7 & 23.5 & $13-100$ & $51.1 *$ & 36.4 \\
\hline
\end{tabular}

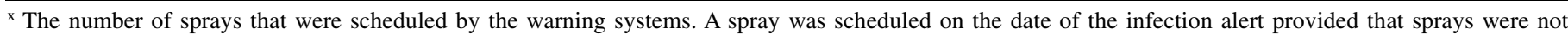
scheduled in the preceding 4 days. CV $=$ year-to-year coefficient of variation (standard deviation $/ \mathrm{mean} \times 100)$.

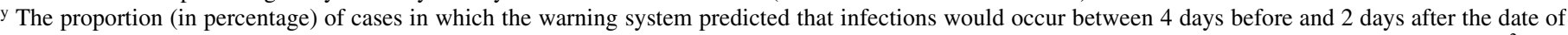
infection. Asterisks indicate that the success rate differs significantly from the success rate of the 5-day schedule treatment $(100 \%)$, as determined by $\chi^{2}$ test (at $P \leq 0.05)$.

${ }^{z}$ FBCA = the Fire Blight Control Advisory system; BIS95 = Billing's Integrated System, 1995.

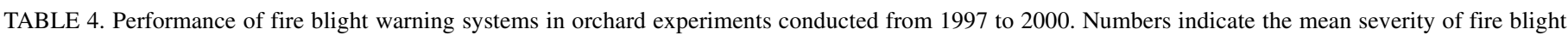

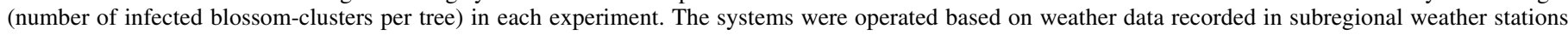
located near the orchards

\begin{tabular}{|c|c|c|c|c|c|c|c|c|c|c|}
\hline \multirow[b]{2}{*}{ Treatment $^{\mathrm{y}}$} & \multicolumn{2}{|c|}{1997} & \multicolumn{3}{|c|}{1998} & \multicolumn{4}{|c|}{1999} & \multirow{2}{*}{$\begin{array}{c}2000 \\
\text { Exp. } 1\end{array}$} \\
\hline & Exp. 1 & Exp. 2 & Exp. 1 & Exp. 2 & Exp. 3 & Exp. 1 & Exp. 2 & Exp. 3 & Exp. 4 & \\
\hline Untreated & $29.4 \mathrm{a}^{\mathrm{z}}$ & $15.0 \mathrm{a}$ & $14.1 \mathrm{a}$ & $30.0 \mathrm{a}$ & $157.0 \mathrm{a}$ & $14.0 \mathrm{a}$ & $18.5 \mathrm{a}$ & $34.1 \mathrm{a}$ & $162.3 \mathrm{a}$ & $217.5 \mathrm{a}$ \\
\hline 5-days & $5.0 \mathrm{~b}$ & $2.6 \mathrm{~b}$ & $2.3 \mathrm{~b}$ & $13.7 \mathrm{bc}$ & $25.0 \mathrm{~b}$ & $4.5 \mathrm{~b}$ & $4.4 \mathrm{~b}$ & $4.2 \mathrm{~b}$ & $17.4 \mathrm{~b}$ & $16.2 b$ \\
\hline FBCA & $\ldots$ & $\ldots$ & $2.4 \mathrm{~b}$ & $8.2 \mathrm{c}$ & $28.2 \mathrm{~b}$ & $2.3 \mathrm{~b}$ & $3.9 \mathrm{~b}$ & $4.8 \mathrm{~b}$ & $31.2 \mathrm{~b}$ & $9.2 \mathrm{~b}$ \\
\hline MARYBLYT 4.3 & $10.2 \mathrm{~b}$ & $16.4 \mathrm{a}$ & $1.1 \mathrm{~b}$ & $23.6 \mathrm{ab}$ & $154.2 \mathrm{a}$ & $\ldots$ & $\ldots$ & $\ldots$ & $\ldots$ & $\ldots$ \\
\hline
\end{tabular}

y Sprays were applied on a 5-day schedule during bloom or according to the Fire Blight Control Advisory (FBCA) or the MARYBLYT 4.3 systems.

${ }^{\mathrm{z}}$ Within a column, data followed by a common letter do not differ significantly $(P \leq 0.05)$ as determined by Fisher's protected LSD test. 
3). Analysis of the results of the five orchard experiments where recommendations of MARYBLYT 4.3 were implemented supports the conclusion derived from the simulation experiments concerning the variable success of that system. In only two of the orchard experiments were disease severity in plots treated according to MARYBLYT 4.3 significantly lower than that recorded in the untreated control plots. In comparison, using FBCA resulted in adequate disease suppression in all eight experiments (Table 4). Differences in the performance of the systems did not result only from the number of sprays applied, but also from the timing of application (Table 1).

The inappropriateness of MARYBLYT 4.3, BIS95, and Cougarblight 98C to Israeli conditions has nothing to do with their biological validity. As already indicated, all systems were thoroughly tested in their places of origin and found sufficiently accurate (8, 21,37). Over the years, the different versions of the MARYBLYT and Billing systems have been extensively used in independent tests. In some, the systems were found accurate. For example, tests in southwest Germany $(25,26)$, Poland (39), Belgium (12), Ontario, Canada (11), California (16), and New Zealand (15) confirmed the accuracy of MARYBLYT, and tests conducted in southwest Germany $(25,26)$, the Netherlands (23), Belgium (12), Italy (2), Poland (38), and Ontario, Canada (10) confirmed the accuracy of BIS95. In other tests, however, the MARYBLYT and Billing systems were not accurate in at least some of the experiments presented in the reports. For MARYBLYT this was reported from Greece (45), Michigan (20), and the northwestern United States (37), and for BIS95 from the Mid-Atlantic States in the United States (49), Turkey $(13,44)$, Sweden (27), and Egypt (1).

What is the reason for the variable performance of the warning systems in our experiments and in other reports? As indicated earlier, most (if not all) of the warning systems developed for fire blight prediction are qualitative and empirical (22). MARYBLYT 4.3, BIS95, Cougarblight 98C, and FBCA definitely fit those criteria. Thus, their development was based, at least to some extent, on observations made in orchards and the circumstances present at the time of probable infection. Although the weather in a specific region may vary from year to year, differences among regions and countries are occasionally larger. Moreover, an environmental factor that governs the occurrence of disease outbreak in one region (because of its scarcity) may have little or no importance in other places (because of its abundance). Use of warning systems that were developed in regions with dissimilar conditions may lead to false-positive and false-negative predictions. Both were observed in our simulation experiments for the imported systems. A false-negative prediction can be demonstrated in our study for the sample orchard-plot in 1998 (Fig. 2). On $30 \mathrm{March}$, the average temperature was $11.3^{\circ} \mathrm{C}$ (the minimum and maximum temperatures were 6.7 and $16.0^{\circ} \mathrm{C}$ ) and on 31 March these respective temperatures were $11.8,7.0$, and $16.6^{\circ} \mathrm{C}$. The daily wetness duration on these days was approximately $20 \mathrm{~h}$. On the previous 3 days, the maximum temperatures were 19 to $23^{\circ} \mathrm{C}$. As the rules of MARYBLYT 4.3 were not met on 30 and 31 March (i.e., the average temperature was less than the $15.6^{\circ} \mathrm{C}$ threshold), infection alerts were not issued. However, infections did occur on those dates and orchards that were not protected with oxolinic acid were severely infected. In fact, experiment 3 in 1998 (Table 4) was conducted in an orchard located in Rosh Pina. In this experiment, severe epidemics developed in untreated plots as well as in plots managed according to MARYBLYT 4.3, as sprays were not applied in those plots. On the other hand, in plots managed according to the FBCA, as well as those under the 5-day schedule treatment, disease was adequately suppressed as sprays were applied on time. In that year, more than 200 ha of pear trees were severely infected due to fire blight infections in northern Israel. Most of the damage had resulted from the 30 and 31 March infection episode $(33,34)$.
A false-positive prediction can be demonstrated in our study for the sample orchard-plot of 2000 (Fig. 2). According to BIS95, infections are feasible without wetting when the maximal temperature is $27^{\circ} \mathrm{C}$ or more and/or the mean temperature is $20^{\circ} \mathrm{C}$ or more (7). In the first 3 weeks of April 2000, those criteria were met on 11 of the days. However, analysis of disease onset and spraying data of orchard-plots located in the Rosh Pina subregion suggest that only two infection episodes occurred in that subregion in 2000. Based on our observations, it seems likely that wetness, rather than temperature, is the factor that governs the occurrence of blossom infections by E. amylovora in Israel, because threshold temperatures for epiphytic growth of the pathogen are often achieved during bloom. Thus, it is not surprising that warning systems that were developed in regions where rains during bloom are frequent and high temperatures are rare are not accurate under the local conditions.

In a study conducted recently under controlled conditions, the interacting effects of temperature, wetness duration, and inoculum size on the development of fire blight symptoms were determined in detached pear blossoms (H. Shwartz, D. Shtienberg, and G. Kritzman, unpublished data). It was expected that quantifying the relationships between these factors would enable us to replace the decision rules used by FBCA with equations based on statistical analysis and thus, to change FBCA from an empirical to a fundamental warning system. Analyses of the data revealed highly significant interactions between the factors tested. It was further demonstrated that the effects of the interaction of these factors on the incidence of blossom infection might be understood in terms of the general concept of compensation. According to this concept, conditions highly favorable for one of the factors essential for pathogen development may compensate for other factors, for which the conditions are less favorable. As a result of the complex interactions observed between the biotic and abiotic factors, because of compensation relationships, and because some of the factors cannot be estimated adequately (e.g., inoculum level), it was concluded that it is not yet possible to incorporate in the FBCA system equations depicting the quantitative relationships between the biotic and abiotic factors tested.

The conclusion derived from the present study is that it is not possible to successfully implement and use in Israel qualitative empirical fire blight warning systems that were developed in regions with dissimilar conditions. Accordingly, it was decided to recommend using the local fire blight warning system, FBCA. In 2001 and 2002, pear growers in Israel operated the FBCA system commercially, and fire blight was suppressed adequately in all the orchards where growers followed its recommendations. On the other hand, severe epidemics developed in some orchards where growers did not apply sprays on time. The FBCA system will continue to be recommended for use in the coming seasons.

\section{ACKNOWLEDGMENTS}

The authors acknowledge the assistance of F. Klietman in the lab work. This research was supported in part by the Chief Scientist of the Israeli Ministry of Agriculture and by the Council of Fruit Trees. Contribution 536/01 from the Agricultural Research Organization, the Volcani Center, Bet Dagan 50250, Israel.

\section{LITERATURE CITED}

1. Abo-El-Dahab, M. K., El-Goorani, M. A., Scheib, A. A., and Zeller, W. 1990. Predictor of fire blight disease in Egypt. Acta Hortic. 273:115-119.

2. Bazzi, C., Gasser, M., and Mazzicchi, U. 1984. Weather analysis with Billing's spring system in relation to the potential risk of fire blight outbreaks in Italy. Acta Hortic. 151:97-106.

3. Bereswill, S., Pahl, A., Bellemann, P., Zeller, W., and Geider, K. 1992. Sensitive and species-specific detection of Ewrinia amylovora by polymerase chain reaction. Appl. Environ. Microbiol. 58:3522-3526.

4. Berger, F., Zeller, W., Gutsche, V., and Rossberg, D. 1996. A new fire blight forecasting system with first results in southwest Germany. Acta 
Hortic. 411:155-161.

5. Billing, E. 1980. Fire blight in Kent, England, in relation to weather (1955-1976). Ann. Appl. Biol. 95:341-364.

6. Billing, E. 1980. Fire blight (Erwinia amylovora) and weather: A comparison of warning systems. Ann. Appl. Biol. 95:365-377.

7. Billing, E. 1996. BIS95, an improved approach to fire blight risk assessment. Acta Hortic. 411:121-126.

8. Billing, E. 1999. Fire blight risk assessment: Billing's integrated system (BIS) and its evaluation. Acta Hortic. 489:399-405.

9. Billing, E. 2000. Fire blight risk assessment systems and modeling. Pages 293-318 in: Fire Blight: The Disease and Its Causative Agent, Erwinia amylovora. J. L. Vanneste, ed. CAB International, Wallingford, U.K.

10. Bonn, W. G. 1987. Potential for fire blight activity in Ontario. Acta Hortic. 217:101-112.

11. Bonn, W. G. 1996. Maryblyt 4.2: Evaluating the program for the prediction of blossom blight of apple and pear. Acta Hortic. 411:173175.

12. Deckers, T., Daemen, E., and Hayen, I. 1996. Fire blight control under temperate zone climatology. Acta Hortic. 411:417-426.

13. Demir, G., and Üstün, N. 1999. Comparison of different prediction systems for blossom blight risk assessment on pear and apple in Aegean region of Turkey. Acta Hortic. 489:419-428.

14. Fry, W. E. 1982. Principles of Plant Disease Management. Academic Press, London.

15. Gouk, S. C., Bedford, R. J., Hutchings, S. O., Cole, L., and Voyle, M. D. 1996. Evaluation of the Maryblyt model for predicting fire blight blossom infection in New Zealand. Acta Hortic. 411:109-116.

16. Holtz, B. A., Teviotdale, B., and Turini, T. 1999. Comparison of models to predict the occurrence of fire blight in the San Joaquin valley of California. Acta Hortic. 489:437-443.

17. Ishimaru, C., and Klos, E. J. 1984. A new medium for detecting Erwinia amylovora and its use in epidemiological studies. Phytopathology 74:1342-1345

18. Jaquart-Romon, C., and Paulin, J. P. 1991. A computerized warning system for fire blight control. Agronomie 11:511-519.

19. Johnson, K. B., and Stockwell, V. O. 1998. Management of fire blight: A case study in microbial ecology. Annu. Rev. Phytopathol. 36:227-248.

20. Jones, A. L. 1992. Evaluation of the computer model Maryblyt for predicting fire blight blossom infection on apple in Michigan. Plant Dis. 76:344-347.

21. Lightner, G. W., van der Zwet, T., and Steiner, P. W. 1999. Fifteen years summary of the efficacy of the Maryblyt prediction system on apple in West Virginia (1984-1998). Acta Hortic. 489:445-447.

22. Madden, L. V., and Ellis, M. A. 1988. How to develop plant disease forecaster. Pages 191-208 in: Experimental Techniques in Plant Disease Epidemiology. J. Kranz and J. Rotem, eds. Springer-Verlag, Berlin.

23. Meijnecke, C. A. R., and Van Teylingen, M. 1981. The development of fire blight in the Netherlands during 1979 and its explanation by the system Billing. Acta Hortic. 117:25-30.

24. Mills, W. D. 1955. Fire blight development on apple in Western New York. Plant Dis. Rep. 39:206-207.

25. Moltmann, E. 1996. Experience with different prediction systems for control of fire blight in southwest Germany. Acta Hortic. 411:131137.

26. Moltmann, E. 1999. Fire blight control with streptomycin according to prediction systems in southwest Germany. Acta Hortic. 489:393-397.

27. Persson, P. 1996. Weather observations and fire blight outbreaks in Sweden 1986-1995. Acta Hortic. 411:139-142.

28. Powell, D. 1965. Factors influencing the severity of fire blight infections on apple and pear. Mich. State Hortic. Soc. Annu. Meet. 94:1-7.

29. Schroth, M. N., Thomson, S. V., Hildebrand, D. C., and Moller, W. J.
1974. Epidemiology and control of fire blight. Annu. Rev. Phytopathol. 12:389-412.

30. Shabi, E., and Zutra, D. 1987. Outbreaks of fire blight in Israel in 1985 and 1986. Acta Hortic. 217:23-30.

31. Shtienberg, D., and Fry, W. E. 1990. Influence of host resistance and crop rotation on the initial appearance of potato early blight. Plant Dis. 74:849-852.

32. Shtienberg, D., Kritzman, G., Herzog, Z., Oppenheim, D., Zilberstaine, M., and Blatchinsky, D. 1999. Development and evaluation of a decision support system for management of fire blight in pears. Acta Hortic. 489:385-392.

33. Shtienberg, D., Oppenheim, D., Herzog, Z., Zilberstaine, M., and Kritzman, G. 2000. Fire blight of pears in Israel: Infection, prevalence, intensity and efficacy of management actions. Phytoparasitica 28:361374.

34. Shtienberg, D., Shwartz, H., Manulis, S., Kritzman, G., Zilberstaine, M., Oppenheim, D., and Herzog, Z. 2003. Coping with fire blight in pears: Experience gained in Israel in the fire blight management (Fire-Man) project. Acta Hortic. 590:253-262.

35. Shtienberg, D., Zilberstaine, M., Oppenheim, D., Herzog, Z., Manulis, S., Shwartz, H., and Kritzman, G. 2001. Efficacy of oxolinic acid and other bactericides in suppression of Erwinia amylovora in pear orchards in Israel. Phytoparasitica 29:143-154.

36. Smith, T. J. 1993. A predictive model for forecasting fire blight of pear and apples in Washington State. Acta Hortic. 338:153-160.

37. Smith, T. J. 1999. Report on the development and use of Cougarblight 98C-A situation-specific fire blight risk assessment model for apple and pear. Acta Hortic. 489:429-436.

38. Sobiczewski, P. 1984. Study on fire blight forecasting. Acta Hortic. 151:91-95

39. Sobiczewski, P., and Berczynsk, S. 1993. Evaluation of Maryblyt for prediction of fire blight on apples in Poland. Acta Hortic. 338:167.

40. Steiner, P. W. 1990. Predicting apple blossom infections by Erwinia amylovora using the MARYBLYT model. Acta Hortic. 273:139-148.

41. Steiner, P. W., and Lightner, G. W. 1996. MARYBLYT 4.3. A predictive program for forecasting fire blight disease in apples and pears. University of Maryland, College Park, MD.

42. Thomson, S. V. 2000. Epidemiology of fire blight. Pages 9-36 in: Fire Blight: The Disease and Its Causative Agent, Erwinia amylovora. J. L. Vanneste, ed. CAB International, Wallingford, U.K.

43. Thomson, S. V., Schroth, M. N., and Moller, W. J. 1982. A forecasting model for fire blight on pears. Plant Dis. 66:576-579.

44. Tokgönül, S., and Cinar, Ö. 1999. Studies on the control possibilities of fire blight by Billing's revised system in the east Mediterranean region of Turkey. Acta Hortic. 489:413-418.

45. Tsiantos, J., and Psallidas, P. G. 1999. Comparison of different fireblight prediction systems under Greek climatic conditions. Acta Hortic. 489:491-494.

46. van der Zwet, T. 1996. Present world-wide distribution of fire blight. Acta Hortic. 411:7-8.

47. van der Zwet, T., and Beer, S. V. 1995. Fire Blight-Its Nature, Prevention, and Control. U.S. Dep. Agric. Bull. No. 631.

48. van der Zwet, T., Biggs, A. R., Heklebower, R., and Lightner, G. W. 1994. Evaluation of the Maryblyt computer model for predicting blossom blight on apple in West Virginia and Maryland. Plant Dis. 78:225-230.

49. van der Zwet, T., Lightner, G., Walter, J., and Steiner, P. W. 1990. Comparison of the Maryblyt predictive model with the Billing revised system for blossom blight risk assessment in apple. Acta Hortic. 273:171-183.

50. Zutra, D., Shabi, E., and Lazarovits, G. 1986. Fire blight on pear, a new disease in Israel. Plant Dis. 70:1071-1073. 